\title{
High Frequency Ultrasound in Determining the Causes of Acute Shoulder Joint Pain
}

\section{Mustafa Z. Mahmoud}

Radiology and Medical Imaging Department, College of Applied Medical Sciences, Prince Sattam Bin Abdulaziz University, Al-Kharj, Saudi Arabia

Email: m.alhassen@psau.edu.sa

How to cite this paper: Mahmoud, M.Z. (2016) High Frequency Ultrasound in Determining the Causes of Acute Shoulder Joint Pain. Open Journal of Radiology, 6, 275-284. http://dx.doi.org/10.4236/ojrad.2016.64036

Received: November 4, 2016

Accepted: December 3, 2016

Published: December 6, 2016

Copyright $\odot 2016$ by author and Scientific Research Publishing Inc. This work is licensed under the Creative Commons Attribution International License (CC BY 4.0).

http://creativecommons.org/licenses/by/4.0/ (c) (i) Open Access

\begin{abstract}
Shoulder ultrasonography is approved as the examination of choice for rotator cuff abnormality in many centers around the world since it is an inexpensive and safe tool for investigation of rotator cuff abnormalities. The goal of this study was to determine the ultrasound findings in patients with acute shoulder joint pain, and also to identify possible predictors of shoulder pain, as well as to compare the ultrasound diagnostic performance to that of MRI in such condition. A total of 65 (mean age 28 \pm 1.2 years) consequential patients were recruited for a period of six months between July 2015 and June 2016 in this study. Collected data were confined on age, medical history, and clinical symptoms. Shoulder ultrasound was performed with a linear array transducer $(10-15 \mathrm{MHz})$ connected to $\mathrm{HI}$ vision Avius ultrasound unit; Hitachi. MRI for the shoulder joint was performed in all cases to confirm the ultrasound results, using 1.5-T MRI system (Magnetom Espree); Siemens. Statistical analysis was completed using the standard Statistical Package for the Social Sciences (SPSS Inc., Chicago, IL, USA) version 20 for windows. Ultrasound manages to determine the causes of acute shoulder joint pain in $98 \%$ of the patients. Fitted achievement values for shoulder ultrasound in the diagnosis the causes of shoulder joint pain were $100 \%$ sensitivity and a range of $96 \%$ to $100 \%$ of accuracy. Ultrasound presents a high sensitivity and accuracy in diagnosis a wide spectrum of shoulder joint lesions, with a diagnostic performance near to that of MRI.
\end{abstract}

\section{Keywords}

High Frequency Ultrasound, Magnetic Resonance Imaging, Prospective Cohort Study, Rotator Cuff, Shoulder Joint

\section{Introduction}

One of the most frequent motives of shoulder pain is rotator cuff disease. It is the third 
most efficacious musculoskeletal malady after low back and neck pain. Shoulder pain is usually due to one of several reasons: subacromial impingement and bursopathy, tendinopathy, a tendon tear, a frozen shoulder, ligamentous instability, and osteoarthritis [1]. There are several examination techniques that can be applied to diagnose rotator cuff disorders, containing sonography, magnetic resonance imaging (MRI), magnetic resonance arthrography, and computed tomographic arthrography. However, Shoulder ultrasonography is approved as the examination of choice for rotator cuff abnormality in many centers around the world since it is an inexpensive and safe tool for investigation of rotator cuff abnormalities [2] [3] [4] [5] [6]. Although, ultrasound is greatly operator dependent, and absolute education of the sonologist is necessary to warrant full sensitivity and specificity of the diagnostic information gained. Dynamic studies and instant patient feedback are other benefits of ultrasound [6].

Sonographic findings serve the orthopedic surgeon to determine whether management should be surgical or nonsurgical; if arthroscopy is denoted, sonographic findings assist the orthopedic surgeon advise patients about surgical and functional outcomes. If a nonsurgical access is preferred, sonography can be applied to follow patients for tear size sequence [7]. Sonography has also been shown to be very sensible for diagnosing calcific tendinitis and may be employed to pilot aspiration of calcific deposits. Aspiration has been shown to afford immediate and long-term pain mitigation at 1 year [8]. Sonography is very precise in diagnosing biceps tendon subluxation, dislocation, and rupture, although it was not fitted to discriminate a high-grade $(\geq 70 \%)$ partial thickness tear from a rupture [9]. Shoulder ultrasound has low sensitivity for diagnosing tenosynovitis, tendinopathy, and low-grade partial-thickness tears. Changes to the acromioclavicular joint, such as synovitis, effusion, osteoarthritis, and osteolysis are gracefully diagnosed with sonography [10] [11]. A paralabral cyst, subdeltoid bursal disturbances such as an effusion and bursitis can promptly be diagnosed with sonography [12]. The goal of this study was to determine the ultrasound findings in patients with acute shoulder joint pain, and also to identify possible predictors of shoulder pain, as well as to compare the ultrasound diagnostic performance to that of MRI in such condition.

\section{Materials and Methods}

\subsection{Study Population}

After taking an acceptance from the local ethics committee, a total of 65 (aged 21 to 60 years) consequential patients presenting with acute shoulder pain in the area of the study were examined sonographically. A single sinologist performed shoulder sonography for all selected patients for a period of six months between July 2015 and June 2016 in this prospective cohort study.

All patients selected were male, and females were excluded from the study to avoid postmenopausal consequences on humeral bone compactness. Patients under the age 18 and patients presenting the history of systemic inflammatory disease were contraindicated. Collected data were confined on age, medical history, and clinical symptoms. The patients were treated correspondingly to history, physical investigation, and shoulder 
ultrasonography. Medical records, containing reports of other imaging investigations, were revised.MRI for the shoulder joint was performed in all cases following ultrasound to confirm the results. The MRI examinations were retrospectively and blinded evaluated by the same sonologist, to avoid any potential bias and effect on the interpretation of pathological findings of the shoulder joint.

\subsection{Shoulder Ultrasound Examination Protocol}

Shoulder ultrasound scans by using brightness mode (B-mode) with high frequency and color Doppler were performed in patients using a linear array transducer (10 - 15 $\mathrm{MHz}$ ) connected to $\mathrm{HI}$ vision Avius ultrasound unit; Hitachi. Initial examination was executed under high gain ( $80 \mathrm{~dB}$ to $90 \mathrm{~dB}$ ) sensitivity for more detailed inspection during ultrasonography.

The sonologist sits and faces the patient; while the patient is seated on a rotatable stool. The scanning was performed blinded to the patient dominant side, and a single randomly determined shoulder was scanned in each patient. Shoulder joint routine ultrasound examination protocol, included evaluation of the biceps and subscapularis tendons, supraspinatus, and infraspinatus tendons. When scanning the cuff tendons longitudinally, the long axis of the tendons was approximately $45^{\circ}$ between the sagittal and coronal planes. The transducer is then turned $90^{\circ}$ to visualize the cuff in a short-axis orientation. Glenohumeral joint and the tendons of the infraspinatus and teres minor were evaluated from a posterior approach. The transducer is placed immediately below the scapular spine and angled slightly caudally, to identify the glenohumeral joint and the posterior aspect of the infraspinatus tendon. Sagittal and coronal planes were used to scan the acromioclavicular joint, but it is best evaluated when the transducer is oriented longitudinally along the clavicle. This orientation increases the visualization of the joint space and its bony margins [1] [13]. The integrity of the rotator cuff was recorded, as being the tendons involved, presence of partial or full thickness tears, and the size of any tear. Taking in mind that, tears begin approximately at 15 $\mathrm{mm}$ posteriorly to the intra-articular portion of the biceps tendon [14].

\subsection{Magnetic Resonance Imaging Protocol}

All MRI examinations for each shoulder joint were conducted using 1.5-T high field power MRI system (Magnetom Espree); Siemens. The conventional MRI shoulder procedure comprised of oblique coronal $\mathrm{T}_{2}$-weighted with fat suppression $(2.48 \mathrm{~min}$ ) and $\mathrm{T}_{1}$-weighted turbo spin echo images $\left(5.58 \mathrm{~min}\right.$ ), oblique sagittal $\mathrm{T}_{2}$-weighted turbo spin echo images without fat suppression $(2.36 \mathrm{~min})$ and transverse $\mathrm{T}_{1}$-weighted turbo spin echo images ( $4.52 \mathrm{~min}$ ). A field of view of $16 \mathrm{~cm}$ was applied, the slice thickness was 3 $\mathrm{mm}$, the imaging matrix was $320 \times 224$, and three signals were averaged for each pulse sequence [15].

\subsection{Data Analysis}

The findings were initially summarized as mean $\pm \mathrm{SD}$ in a form of comparison tables 
and graphs. Analysis was accomplished by applying the standard Statistical Package for the Social Sciences (SPSS Inc., Chicago, IL, USA) version 20 for windows.

\section{Results}

In this prospective cohort study a total of 65 patients presented with acute shoulder joint pain were investigated using shoulder musculoskeletal ultrasound. Patient aged from 21 to 60 years; the mean age \pm SD was $28 \pm 1.2$ years. Results concerning medical history and clinical presentations of the patients were presented in (Table 1).

The right shoulder joint was examined sonographically in 37 patients while the left joint was examined in the rest 28 conditions. Ultrasound manages to detect the causes of acute shoulder joint pain in $98 \%$ ( 63 patients out of 65 examined cases) of the patients; such findings were confirmed by using MRI. Overview of these pathological abnormalities was presented in (Table 2) below.

According to shoulder joint ultrasound findings, subscapularis tendon abnormalities where $15.4 \%$ of tendinosis, $10.8 \%$ of partial thickness tear, and $3.1 \%$ affected by full thickness tear. Supraspinatus and infraspinatous tendon were found to be subjected to abnormalities of $15.4 \%$ and $23.1 \%$ tendinosis, $10.8 \%$ and $1.5 \%$ of partial thickness tear, and $3.1 \%$ and $4.6 \%$ of full thickness tear respectively. Atrophy of teres minor tendon was the least abnormality detected $6.2 \%$ when compared to tendinosis of the tendon, which presents by a percentage of $10.8 \%$. Such previously reflected ultrasound findings of rotator cuff abnormalities were demonstrated in (Table 2 and Figure 1).

Musculoskeletal ultrasound of the shoulder joint in patients presented that biceps tendons was affected with tendinosis in $4.6 \%$, while full thickness tear abnormality of the tendon found in $3.1 \%$. Osteoarthritis changes were developed in $16.9 \%$ and $20 \%$ of acromioclavicular and glenohumeral joints consequently. In addition, subluxation and

Table 1. Medical history and clinical presentations in patients with acute shoulder joint pain.

\begin{tabular}{ccc}
\hline \multicolumn{3}{c}{ Medical history and clinical presentation } \\
\hline Medical history & Frequency (n) & Percentage (\%) \\
\hline None & 17 & $26.2 \%$ \\
Trauma/injury & 37 & $56.9 \%$ \\
Joint instability & 11 & $16.9 \%$ \\
\hline Clinical presentation & Frequency (n) & Percentage (\%) \\
\hline Pain/tenderness & 65 & $100 \%$ \\
Swelling & 13 & $20 \%$ \\
Numbness & 7 & $10.8 \%$ \\
Bruising/redness & 16 & $24.6 \%$ \\
Joint weakness & 24 & $36.9 \%$ \\
Joint stiffness & 4 & $6.2 \%$ \\
Clunking sound & 9 & $13.9 \%$ \\
\hline
\end{tabular}


Table 2. Ultrasound findings in acute shoulder joint pain.

\begin{tabular}{|c|c|}
\hline Shoulder joint ultrasound finding & Frequency and percentage (\%) \\
\hline \multicolumn{2}{|l|}{ Biceps tendon abnormalities } \\
\hline Tendinosis & $(3,4.6 \%)$ \\
\hline Full-thickness tear & $(2,3.1 \%)$ \\
\hline \multicolumn{2}{|l|}{ Subscapularis tendon abnormalities } \\
\hline Tendinosis & $(10,15.4 \%)$ \\
\hline Partial thickness tear & $(7,10.8 \%)$ \\
\hline Full thickness tear & $(2,3.1 \%)$ \\
\hline \multicolumn{2}{|l|}{ Supraspinatus tendon abnormalities } \\
\hline Tendinosis & $(15,23.1 \%)$ \\
\hline Partial thickness tear & $(1,1.5 \%)$ \\
\hline Full thickness tear & $(3,4.6 \%)$ \\
\hline \multicolumn{2}{|l|}{ Infraspinatus tendon abnormalities } \\
\hline Tendinosis & $(9,13.9 \%)$ \\
\hline Partial thickness tear & $(3,4.6 \%)$ \\
\hline \multicolumn{2}{|l|}{ Teres minor tendon abnormalities } \\
\hline Tendinosis & $(7,10.8 \%)$ \\
\hline Atrophy & $(4,6.2 \%)$ \\
\hline \multicolumn{2}{|l|}{ Acromioclavicular joint abnormalities } \\
\hline Osteoarthritis & $(11,16.9 \%)$ \\
\hline Subluxation/dislocation & $(6,9.2 \%)$ \\
\hline Posterior labrum abnormality & $(8,12.3 \%)$ \\
\hline \multicolumn{2}{|c|}{ Glenohumeral joint/bony margins abnormalities } \\
\hline Osteoarthritis & $(13,20 \%)$ \\
\hline Subluxation/dislocation & $(4,6.2 \%)$ \\
\hline
\end{tabular}

or dislocation were seen in $9.2 \%$ and $6.2 \%$ for both joints. Much more, the findings in (Table 2 and Figure 2) revealed that a percentage of $12.3 \%$ of posterior labrum abnormality occur in the acromioclavicular joint.

Furthermore, MRI was used to confirm the ultrasound findings regarding the diagnosed causes of shoulder joint pain. MRI proved that ultrasound managed to diagnose correctly the causes of acute shoulder joint pain in 98\% (63 patients out of 65 examined cases) of the patients, as previously mentioned. The calculated performance values for musculoskeletal ultrasound in diagnosing the abnormalities of rotator cuff, biceps tendon, acromioclavicular joint, and glenohumeral joint was 100\% for sensitivity.

Accuracy was $98.4 \%, 100 \%, 96 \%$, and $100 \%$ respectively for the above mentioned disorders. Positive predictive value (PPV) was $100 \%$ for rotator cuff, biceps tendon, and glenohumeral joint disorders, while it was $96 \%$ for the abnormalities developed in the 
acromioclavicular joint (Table 3).

\section{Discussion}

According to the findings of this study, the most common abnormality that leads to the onset of the acute pain in the shoulder joint was tendinosis of supraspinatus tendon with an incidence of $23.1 \%$. Less frequently was the incidence of tendinosis at the subscapularis, infraspinatus, teres minor, and biceps tendons with a percentage of $15.4 \%$, $13.9 \%, 10.8 \%$, and $4.6 \%$ consequently. Such findings were confirmed by as Millar et al., and McKendry et al., where tendinopathies are a highly prevalent problem in musculoskeletal medicine [16] [17].

Although women were excluded from the study to avoid the effects of post menopause on humeral bone compactness, but an increased incidence of osteoarthritis was noted in this study. Osteoarthritis affects both glenohumeral and acromioclavicular joints in a $20 \%$ and $16.9 \%$ consequently (Table 2 and Figure 2), such findings were demonstrated in other research around the visualization of intra-articular constructors of the acromioclavicular joint in an ex vivo model using a dedicated MRI procedure, where these joints were often present degenerative changes start from the third decade of life. Taking in mind, that the higher sensitivity of ultrasound in detection early the symptoms of degenerative changes [18]. More than double incidence of teres minor tendon atrophy was noted in $6.2 \%$ of patients examined in this study (Table 3 and Figure 1), when compared to $3 \%$ of cases ( $n=61$ cases) in another study of teres minor

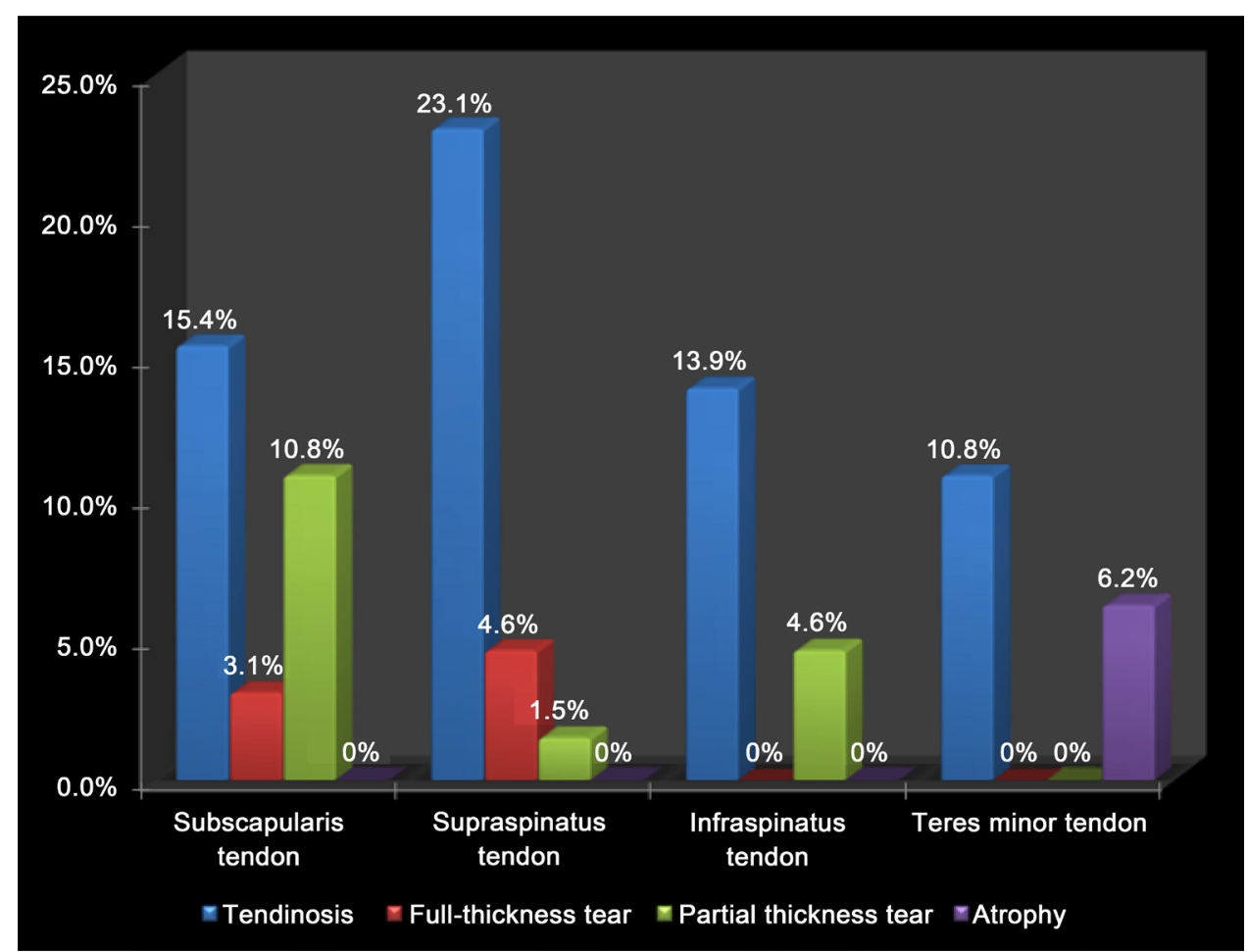

Figure 1. Rotator cuff abnormalities in patients with acute shoulder pian as detected sonographically. 


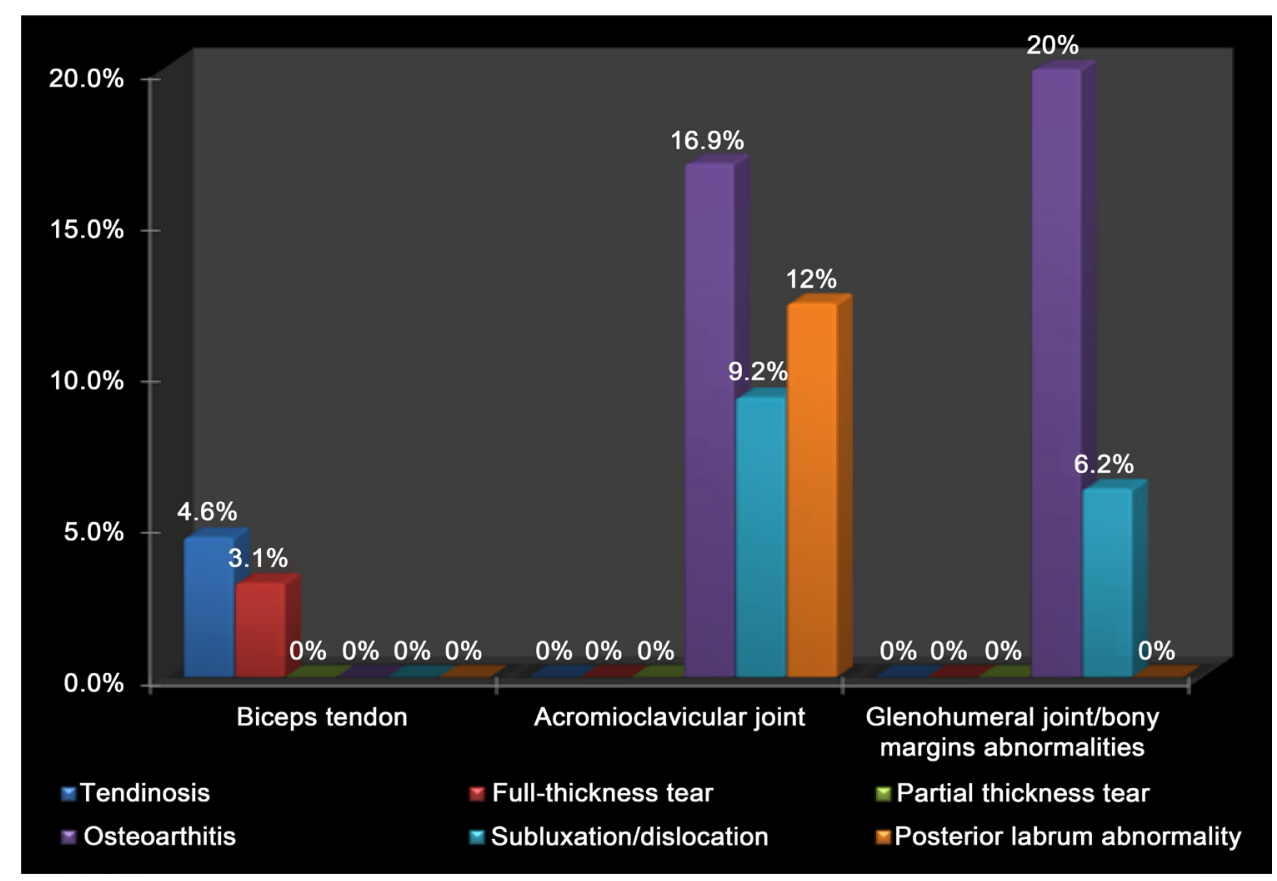

Figure 2. Abnormalities detected sonographically in the biceps tendon, acromiclavicular joint, and glenohumeral joint at the painful shoulders.

Table 3. Performance of musculoskeletal ultrasound in diagnosing abnormalities of rotator cuff, biceps tendon, acromioclavicular joint, and glenohumeral joint.

\begin{tabular}{|c|c|c|c|c|c|c|c|}
\hline $\begin{array}{l}\text { Disorders } \\
\text { location }\end{array}$ & $\begin{array}{l}\text { True } \\
+, \mathrm{n}\end{array}$ & $\begin{array}{l}\text { True } \\
-, \mathrm{n}\end{array}$ & $\begin{array}{l}\text { False } \\
+, \mathrm{n}\end{array}$ & $\begin{array}{l}\text { False } \\
-, \mathrm{n}\end{array}$ & Sensitivity, $\%$ & Accuracy, \% & ${ }^{*} \mathrm{PPV}, \%$ \\
\hline Rotator cuff & 60 & 0 & 0 & 1 & $100 \%$ & $98.4 \%$ & $100 \%$ \\
\hline Biceps tendon & 5 & 0 & 0 & 0 & $100 \%$ & $100 \%$ & $100 \%$ \\
\hline $\begin{array}{c}\text { Acromioclavicuar } \\
\text { joint }\end{array}$ & 24 & 0 & 0 & 1 & $100 \%$ & $96 \%$ & $96 \%$ \\
\hline $\begin{array}{l}\text { Glenohumeral } \\
\text { joint }\end{array}$ & 17 & 0 & 0 & 0 & $100 \%$ & $100 \%$ & $100 \%$ \\
\hline
\end{tabular}

${ }^{\star} \mathrm{PPV}$, positive predictive value.

innervation in the context of isolated muscle atrophy [19]. Such incidence could be explained on the basis that, their study population was presented with a mean age of $72 \pm$ 9 years, which lead directly to minimize atrophy as a finding.

In this study, the incidence of rotator cuff full thickness tear was $7.7 \%$ (Table 2). This rate was a little bit higher than the rate of $7.6 \%$ reported by Moosmaymer et al. [20]. Schibany et al., reported a rate of full thickness tear of 6\%, which is lower than the obtained rate [21]. Respectively Girish et al., and Reilly et al., determined rates of $9.8 \%$ and $21.7 \%$ for full thickness tear, which were higher than the rate obtained in this study [6] [22]. Also findings detected a partial thickness tear of the rotator cuff with an incidence of $16.9 \%$ (Table 2). This percentage of incidence could be compared to the results of Girish et al., and Milgorm et al., where they reported an incidence of $18 \%$ and 
$17.2 \%[6][23]$.

Regarding the study results, shoulder ultrasound found to be a $100 \%$ accurate in the diagnosis of abnormalities affect biceps tendon and glenohumeral joint. Much more, an accuracy of $98.4 \%$ and $96 \%$ noted for the detection of both rotator cuff and acromioclavicular joint disorders (Table 3). Although the literature on the accuracy, sensitivity, and PPV of shoulder ultrasound in detection the causes of acute shoulder joint pain is scant, but an accuracy of $94 \%$ and $81 \%$ for shoulder ultrasound in the diagnosing of full and partial thickness tears of the rotator cuff, were reported in a study of the effectiveness of diagnostic tests for the assessment of shoulder pain due to soft tissue disorders [24].

The first limitation of this study was its small sample size that was limited to men, made this study not representative of the whole population. Secondly, clinical follow-up was unavailable for patients; thus, there were no results concerning the achievement of shoulder ultrasound in this group of patients in need for follow-up. However, this study manages to determine accurately the causes of acute shoulder joint pain, as proved by using MRI modality.

\section{Conclusion}

In conclusion, ultrasound for the shoulder joint presents a high accuracy and sensitivity in diagnosis a wide spectrum of shoulder joint lesions, with a diagnostic performance value near to that of MRI. Furthermore, it is a real time investigation that can afford comparison information of the two joints. There is also the possibility to reciprocate with the patient and demonstrate the results of the study. However, it is necessary to learn that it is impeding to envisage the entire cuff in obese patients and in patients with reduced range of movement or frozen shoulder as well.

\section{Acknowledgements}

The author would like to thank the staff of the Radiology and Medical Imaging Department of Prince Sattam bin Abdulaziz University Hospital for their cooperation and support during data collection.

\section{References}

[1] Teefey, S.A. (2012) Shoulder Sonography: Why We Do It. Journal of Ultrasound in Medicine, 31, 1325-1331.

[2] Teefey, S.A., Hasan, S.A., Middleton, W.D., et al. (2000) Ultrasonography of the Rotator Cuff: A Comparison of Ultrasonographic and Arthroscopic Findings in One Hundred Consecutive Cases. The Journal of Bone \& Joint Surgery, 82, 498-504.

https://doi.org/10.2106/00004623-200004000-00005

[3] Prickett, W.D., Teefey, S.A., Galatz, L.M., et al. (2003) Accuracy of Ultrasound Imaging of the Rotator Cuff in Shoulders That Are Painful Postoperatively. The Journal of Bone \& Joint Surgery, 85, 1084-1089. https://doi.org/10.2106/00004623-200306000-00016

[4] Teefey, S.A., Rubin, D.A., Middleton, W.D., et al. (2004) Detection and Quantification of Rotator Cuff Tears: Comparison of Ultrasonographic, Magnetic Resonance Imaging, and 
Arthroscopic Findings in Seventy-One Consecutive Cases. The Journal of Bone \& Joint Surgery, 86, 708-716. https://doi.org/10.2106/00004623-200404000-00007

[5] Al-Shawi, A., Badge, R. and Bunker, T. (2008) The Detection of Full Thickness Rotator Cuff Tears Using Ultrasound. The Journal of Bone \& Joint Surgery, 90, 889-892. https://doi.org/10.1302/0301-620X.90B7.20481

[6] Girish, G., Lobo, L.G., Jacobson, J.A., et al. (2011) Ultrasound of the Shoulder: Asymptomatic Findings in Men. American Journal of Roentgenology, 97, W713-W719. https://doi.org/10.2214/ajr.11.6971

[7] Goutallier, D., Postel, J.M., Gleyze, P., Leguilloux, P. and Van Driessche, S. (2003) Influence of Cuff Muscle Fatty Degeneration on Anatomic and Functional Outcomes after Simple Suture of Full-Thickness Tears. Journal of Shoulder and Elbow Surgery, 12, 550-554. https://doi.org/10.1016/S1058-2746(03)00211-8

[8] Serafini, G., Sconfienza, L.M., Lacelli, F., et al. (2009) Rotator Cuff Calcific Tendonitis: Short-Term and 10-Year Outcomes after Two-Needle US-Guided Percutaneous TreatmentNonrandomized Controlled Trial. Radiology, 252, 157-164.

https://doi.org/10.1148/radiol.2521081816

[9] Skendzel, J.G., Jacobson, J.A., Carpenter, J.E.W. and Miller, B.S. (2011) Long Head of Biceps Brachii Tendon Evaluation: Accuracy of Preoperative Ultrasound. American Journal of Roentgenology, 197, 942-948. https://doi.org/10.2214/AJR.10.5012

[10] Ferri, M., Finlay, K., Popowich, T., Jurriaans, E. and Friedman, L. (2005) Sonographic Examination of the Acromioclavicular and Sternoclavicular Joints. Journal of Clinical Ultrasound, 33, 345-355. https://doi.org/10.1002/jcu.20153

[11] Armstrong, A., Teefey, S.A., Wu, T., et al. (2006) The Efficacy of Ultrasound in the Diagnosis of Long Head of the Biceps Tendon Pathology. Journal of Shoulder and Elbow Surgery, 15, 7-11. http://dx.doi.org/10.1016/j.jse.2005.04.008

[12] Van Holsbeeck, M. and Strouse, P.J. (1993) Sonography of the Shoulder: Evaluation of the Subacromial-Subdeltoid Bursa. American Journal of Roentgenology, 160, 561-564. http://dx.doi.org/10.2214/ajr.160.3.8430553

[13] Kim, H.M., Dahiya, N., Teefey, S.A., Keener, J.D. and Yamaguchi, K. (2008) Sonography of the Teres Minor: A Study of Cadavers. AJR. American Journal of Roentgenology, 190, 589-594. http://dx.doi.org/10.2214/AJR.07.2960

[14] Kim, H.M., Dahiya, N., Teefey, S.A., et al. (2010) Location and Initiation of Degenerative Rotator Cuff Tears: An Analysis of Three Hundred and Sixty Shoulders. The Journal of Bone and Joint Surgery. American Volume, 92, 1088-1096. https://doi.org/10.2106/JBJS.I.00686

[15] Rutten, M.J., Spaargaren, G.J., van Loon, T., et al. (2010) Detection of Rotator Cuff Tears: the Value of MRI Following Ultrasound. European Radiology, 20, 450-457. http://dx.doi.org/10.1007/s00330-009-1561-9

[16] Millar, N.L., Reilly, J.H., Kerr, S.C., et al. (2012) Hypoxia: A Critical Regulator of Early Human Tendinopathy. Annals of the Rheumatic Diseases, 71, 302-310. http://dx.doi.org/10.1136/ard.2011.154229

[17] McKendry, R.J.R., Uhthoff, H.K., Sarkar, K. and Hyslop, P.S. (1982) Calcifying Tendinitis of the Shoulder: Prognostic Value of Clinical, Histologic, and Radiologic Features in 57 Surgically Treated Cases. The Journal of Rheumatology, 9, 75-80.

[18] Fialka, C., Krestan, C.R., Stampfl, P., et al. (2005) Visualization of Intraarticular Structures of the Acromioclavicular Joint in an Ex Vivo Model Using a Dedicated MRI Protocol. AJR. American Journal of Roentgenology, 185, 1126-1131. 
http://dx.doi.org/10.2214/AJR.04.1433

[19] Friend, J., Francis, S., McCulloch, J., et al. (2010) Teres Minor Innervation in the Context of Isolated Muscle Atrophy. Surgical and Radiologic Anatomy, 32, 243-249.

http://dx.doi.org/10.1007/s00276-009-0605-9

[20] Moosmayer, S., Smith, H.J., Tariq, R. and Larmo, A. (2009) Prevalence and Characteristics of Asymptomatic Tears of the Rotator Cuff: An Ultrasonographic and Clinical Study. Journal of Bone and Joint Surgery-British Volume, 91, 196-200. http://dx.doi.org/10.1302/0301-620X.91B2.21069

[21] Schibany, N., Zehetgruber, H., Kainberger, F., et al. (2004) Rotator Cuff Tears in Asymptomatic Individuals: A Clinical and Ultrasonographic Screening Study. European Journal of Radiology, 51, 263-268. http://dx.doi.org/10.1016/S0720-048X(03)00159-1

[22] Reilly, P., Macleod, I., Macfarlane, R., Windley, J. and Emery, R.J. (2006) Dead Men and Radiologists Don't Lie: A Review of Cadaveric and Radiological Studies of Rotator Cuff Tear Prevalence. Annals of the Royal College of Surgeons of England, 88, 116-121. http://dx.doi.org/10.1308/003588406X94968

[23] Milgrom, C., Schaffler, M., Gilbert, S. and van Holsbeeck, M. (1995) Rotator-Cuff Changes in Asymptomatic Adults: The Effect of Age, Hand Dominance and Gender. Journal of Bone and Joint Surgery-British Volume, 77, 296-298.

[24] Dinnes, J., Loveman, E., McIntyre, L. and Waugh, N. (2003) The Effectiveness of Diagnostic Tests for the Assessment of Shoulder Pain Due to Soft Tissue Disorders: A Systematic Review. Health Technology Assessment, 7, 1-166. http://dx.doi.org/10.3310/hta7290

Submit or recommend next manuscript to SCIRP and we will provide best service for you:

Accepting pre-submission inquiries through Email, Facebook, LinkedIn, Twitter, etc. A wide selection of journals (inclusive of 9 subjects, more than 200 journals)

Providing 24-hour high-quality service

User-friendly online submission system

Fair and swift peer-review system

Efficient typesetting and proofreading procedure

Display of the result of downloads and visits, as well as the number of cited articles Maximum dissemination of your research work

Submit your manuscript at: http://papersubmission.scirp.org/

Or contact ojrad@scirp.org 